\title{
The Implication of Textile Materials Applied in Preventing the Spread of COVID-19
}

\author{
Shaikh Md Mominul Alam ${ }^{1}$ and Shariful Islam ${ }^{2 *}$ \\ ${ }^{1}$ Department of Textile Machinery Design and Maintenance, Faculty of Science and Engineering, Bangladesh University of \\ Textiles, Tegjaon, Dhaka, Bangladesh
}

${ }^{2}$ Department of Fabric Engineering, Bangladesh University of Textiles. Tegjaon, Dhaka, Bangladesh

*Corresponding author: Shariful Islam, Department of Fabric Engineering, Bangladesh University of Textiles. Tegjaon, Dhaka,

1208, Bangladesh

\section{ARTICLE INFO}

Received: 蔧 June 29, 2020

Published: 幽 July 15, 2020

Citation: Shaikh Md Mominul A, Shariful Islam. The Implication of Textile Materials Applied in Preventing the Spread of COVID-19. Biomed J Sci \& Tech Res 28(5)-2020. BJSTR. MS.ID.004721.

Keywords: COVID 19; Coronavirus Pandemic; Center for Disease Control (CDC); World Health Organization (WHO); N95 Mask; Readymade Garments (RMG); Personal Protective Equipment (PPE)

\section{ABSTRACI}

The aim of this paper is to discuss the implication of textile materials in preventing the spread of COVID 19. Textile materials are beneficial for the preparation of personal protective equipment (PPE) and these equipment's are required for the treatments of COVID 19 patients those are deliberated briefly in this paper. The findings of this paper established that medical textiles such as surgical masks, gloves, gowns, shoe covers, sleeve covers etc are essential to get protection against COVID 19. Coronavirus has some symptoms like high fever, dry cough, sneeze, throat pain, breathing problems etc. This virus spread by intimacy from person to person like hand shaking, embracing, close body contact etc. Even this virus spread from contaminated surface that contains COVID 19 germs. Sometimes this virus spread without intimacy like sneezing and cough. By using medical textile products such as hand gloves, masks, surgical caps, apron, shoe cover, sleeve covers etc can definitely reduce the contagion process of this virus. Doctors, nurses and medical assistances are using these personal protective equipment's to get protection against this virus. Until May 2020, no specific vaccine or medicine has been invented that can prevent or cure from this virus attack. But, only personal awareness and protection can be a great solution to be safe from the attack of this virus. And definitely, medical textiles are playing vital roles to fight against pandemic COVID 19 virus attack. This paper is beneficial to the personnel involved in public health studies, social science studies and COVID 19 virus attack studies who are in charge of reviewing textiles materials and to find out their applications. This paper opens probable techniques for the researchers to further study in this field.

\section{Introduction}

This study is of great importance in the field of textiles, social science and public health. Different scholars worked at various times related to this research as literary reviews differ information as well. Which had some similarities and some of them was different. Researchers from the United States and laboratories have studied the durability of the SARS-Cavi-1 virus on different surfaces, proving that copper and cardboard were better than plastic and stainless steel. After eight hours there was no measurable CoV-1 SARV virus in the copper and cardboard. In addition, the study concluded that viruses no longer exist in cellulose. Extensive research on cotton has shown that improved application of cotton, such as toxic chemical compounds and oil absorption systems, is important against the spread of COVID19. Researcher reported the symptoms, contagious process, prevention and post treatments of COVID 19. This virus is infected from person to person and also infected by contaminated from surface to person [1]. The International Labor Organization estimates that 195 million jobs could be lost.

Many American partners send out notices to their Vietnamese partners for three to four weeks to cancel their clothing and clothing receipts. Nearly half of all textile exports from HCM City go to the United States. According to Wit Thang chief Jean Pham Van Wit, Chinese experience has shown that it will take at least two months to control the epidemic. Incomes in the spinning, fabrics, leather and shoe factories are deteriorating, as employees are being 
told to stay home, close factories and blackout worldwide supply chains. The cancellation of the order severely affected thousands of companies and millions of workers. We urgently need to provide solidarity and joint action across the supply chain. Researcher also reported that the textile materials are applied in human medical treatment purpose [2]. The ILO is committed to assisting government in maintaining the health and economic well-being of workers and businessmen in the textile, clothing, leather and footwear industries. Bangladesh's export income is increasingly dependent on the readymade (RMG) sector. Now due to this incident, the economy of our country is under threat. Because, $84 \%$ remittances were received from these regions.

The coronavirus epidemic is a threat to the country's clothing sector, as foreign buyers have begun to revise their trading strategies amid an important situation. Researcher reported that, human health benefits, human comfort properties and natural environment is influenced by natural sustainable textile fibers [3]. The Bangladesh Textile Manufacturers and Exporters Association (BGMEA) stated that order cancellation notices or shipments from buyers were delayed for export orders worth more than US $\$ 3$ billion to over one thousand RMG factories. It is affecting more than 1.44 million workers. An outbreak of corona virus is a human tragedy and economic disaster, but in the long term some businesses can do far better than this. Take the UK textile industry. During the 1990s, British textile companies lost a lot of business to China, as clothing retailers and brands in the UK entered the Far East for cheap production. But deviations from trade with China forced some retailers to fully reconsider the wisdom of the supply chain and turn to British manufacturers [4].

Manufacturers like Master and Kapadia have their own supply chain concerns. Many of their raw materials come from abroad and from countries that are severely affected by the Corona virus. Italy, for example, is a great supplier of yarn. The Kovid-19 epidemic had a profound effect on demand in the supply sector and the garment sector. Large exporters like Bangladesh are feeling the heat due to raw material societal challenges and order cancellations. Reliance in the same country as a major supplier may not be very effective in the future, which will allow countries like India, Bangladesh, Vietnam, Russia and Indonesia to diversify into value-added clothes. Why is this important? This economy decreased due to this.. 6\%, high equipment activities from other countries will be justified soon [5]. The performance of the RMG sector is more important for an economy like Bangladesh, where apparel employs about $6 \%$ of the country's exports, and employs about 3.5 million people. When measuring the potential impact of the epidemic on the clothing sector, it is necessary to consider the demand-side situation by analyzing European and American and emerging markets for clothing exports.

With the COVID-19 epidemic, the need for supply chain change, disruption and innovation has become real. With nearly 3 billion people worldwide off, the world will face a new situation. Many governments are working hard to deal with this epidemic. Nonmedical countermeasures such as masks, personal protective equipment and wipes have become life-saving necessities [6]. Definitions of Chinese medical equipment have hurt American coronaviruses, so the United States has made little import from China. According to the Peterson Institute for International Economics, imports of Chinese medicinal products fell 16 percent between 2014 and 2014. Mask production lines that moved from the United States have led to a supply shortage in the country. As per Medegen medical substances, world's manufacture of face masks is presently limited to China and is not applied or cheap for others. All the world's well-known masks manufacturers are American but their actual production takes place outside the United States. Various raw materials such as cotton and mixtures can be explored to develop functional substances. It is necessary to develop a new development map for the textile industry [7].

The ecosystem of innovation needs to be further strengthened, which requires coordination between industry associations, academia and government agencies. Cavid-19 reinforces the need to encourage innovation and retain insider talent. The garment industry has been hit hard worldwide. The store is closed and almost all buyers have a big list so they decide to cancel or postpone. They may not apply in the next few months. Daily wage workers, who make up 80 percent of the workforce in garment factories, are on the streets or in the backyard of their cities. The United States and Europe are the major export destinations of India. It is difficult to say when these countries will return to normal life, and even if they do, how much longer will consumers start spending as the shutdown leads to unemployment. COVID-19 is an infectious disease [8]. It was first identified in December 2019 in Wuhan, China, and has since spread globally, causing an ongoing pandemic. The most common symptoms include fever, cough, fatigue, shortness of breath, and loss of smell and taste.

Although most cases involve mild symptoms, some progress in acute respiratory distress syndrome (ARDS), multi-organ failure, septic shock, and blood clots. The time from exposure to onset of symptoms is typically around five days but can vary from two to fourteen days. The virus spreads mainly among people during close contact, often through small droplets produced by coughing, sneezing, and chattering. People can also be infected by touching a contaminated surface and then touching their faces [9]. On the surface, the amount of virus decreases over time until it is not enough to remain infectious, but can be detected for hours or days. It is most contagious during the first three days after the onset of symptoms, although spreading may be possible before symptoms appear and in later stages of the disease. Recommended measures to prevent infection include frequent hand washing, physical distance from others (especially those with symptoms), quarantine, cough, and unwashed hands from the face. In addition, the use of a face cover is recommended for those who suspect they 
have the virus and their caregivers [10]. Researchers are examining patterns among the growing number of coronavirus patients around the world to find out how typical symptoms progress. According to information from China, mainly general symptoms so far are fever, dry cough, and wheezing, but COVID-19 patients can expand only one or two of these circumstances throughout their illness. Investigation by the Chinese Center for Disease Control has recommended that about $80 \%$ of coronavirus belongings are slight, but even mild cases can be throbbing and enduring. About $15 \%$ of patients in China developed severe cases and around 5\% became seriously ill [11].

\section{The Symptoms of COVID 19}

According to the data from the 1st cases in Wuhan and the inquiries carried out by the Chinese CDC and the local CDC, the incubation time can usually be amid 3 and 7 days and up to 2 weeks, as the lengthiest time from infection to symptoms is 12.5 days state (95\% CI, 9.2 to 18). These data also presented that this novel epidemic be doubled in every seven days, while the base imitation number (R0 - R null) is 2.2. In other words, on average, each patient conveys the infection to an extra 2.2 people [12]. Researchers are investigating patterns amid the growing number of coronavirus patients everywhere the world to find out how characteristic symptoms progress. As per information from China, basically general symptoms so far are fever, dry cough, and wheezing, but COVID-19 patients can enlarge only one or two of these conditions throughout their illness. Research by the Chinese Center for Disease Control has advised that around $80 \%$ of coronavirus cases are mild, but even mild cases can be painful and long-lasting [13]. About $15 \%$ of patients in China improved severe cases and around 5\% as extremely ill. Anyway, the first symptoms basically do not seem directly after a person has been infected. The average incubation time for the virus is nearly five days, but it can range from two to 14 days, as per the US Centers for Disease Control and Prevention [14].

In the first day symptoms showed marginally. Patients may have fever, dry cough, or infrequent wheezing. Some may also feel fatigued and muscle pain. A lesser may have had diarrhea or nausea a day or two earlier. Fever is a key sign of Covid-19. As several people may have a body temperature underneath or overhead 98.6 degrees Fahrenheit (37 degrees Celsius), specialists say they don't set a number. Muscle pain and overall tired feeling are also joint. The WHO reported that about $40 \%$ of the closely 6,000 people with laboratory-confirmed cases had fatigue [15]. A sore throat and a stuffy nose are less common, and a runny nose or sneezing is even less common. The WHO also found that nearly $14 \%$ of the 6,000 cases of Covid-19 in China had symptoms of headache and sore throat, while almost 5\% had nasal cramming. In the fifth day in severe cases, symptoms may start to get worse. Patients may have trouble in breathing, particularly if they are older or have a preexisting health condition. Shortness of breath is usually not an early symptom of Covid-19, but is the most serious [16]. It can happen on its own, deprived of coughing. If your chest contracts or you start feeling that you can't inhale enough to fill your lungs with air, this is a sign to act rapidly, experts say.

In the seventh day this is the normal time it takes for Wuhan patients to be hospitalized after symptoms begin. 15 percent of patients who don't see their symptoms decrease and show signs of dyspnea; they tends to be hospitalized on the seventh day. The CDC informs that anyone who has emergency signs for Covid-19, persistent chest pain or pressure, shortness of breath and bluish lips or face, should receive medical attention [17]. In the eighth day at this time, patients with severe cases have probably developed shortness of breath, pneumonia, or acute respiratory distress syndrome, a condition that may require intubation. ARDS is often fatal. ARDS is a life-threatening condition in which the lungs cannot supply enough oxygen to the vital organs of the body. It occurs when the lungs become severely inflamed due to an infection or injury, and the inflammation causes fluid to leak from the blood vessels near the small air pockets in the lungs, making it difficult to breathe [18]. In the tenth day if patients have worse symptoms, this is the time of disease progression when they are likely to be hospitalized in the ICU. Such patients possibly have more stomach pain and loss of hunger than patients with slighter cases. One study described a unique subset of milder cases where the initial symptoms were digestive problems such as diarrhea, often without fever. In the twelfths day, the fever, an early sign of Covid-19, usually ended [19].

In the thirteenth day, the dyspnea (shortness of breath) tends to stop after about 13 days for those who survive, although it will continue until death for those who have not. In the seventeenth day, on standard, citizens in Wuhan who improved from the virus were released from the hospital after $21 / 2$ weeks. In the eighteenth day, since the onset of the disease, the average death time has been 18.5 days. In the twenty-second day, the average discharge time was 22 days. Currently, there is no vaccine to protect people from the virus. In the twenty-seventh day, some patients stay in the hospital longer. The standard hospital continues for Wenzhou patients was 27 days [20].

\section{The Contagious Process of COVID 19}

The noble coronavirus is extremely spreadable, which means it extents simply from person to person. According to the CDC Trusted source, people who have the virus are more contagious when they show symptoms of COVID-19. Although much less common, there is a chance that someone infected with the coronavirus could transmit the virus even if they do not show symptoms. It is also possible that the virus is spread by touching virus-contaminated surfaces and then touching your mouth or nose. However, this is not the main way the new coronavirus is spread [21]. Some details on how the disease is spreading are still being determined. WHO and U.S. Centers for Disease Control and Prevention (CDCP), they say it 
mainly spreads in close contact and from small droplets produced when people cough, sneeze or speak in close contact within about 1-2 m(3-7 feet). Together mucus and spittle can transmit big virusrelated piles. Speaking out loud releases more falls than speaking normally. A Singapore study found that an uncovered cough can lead to droplets traveling up to 4.5 meters (15 feet) [22].

As with other respiratory pathogens, such as influenza and rhinovirus, the transmission is believed to occur through respiratory droplets from coughing and sneezing. The transmission of aerosols is also possible in case of prolonged exposure to high concentrations of aerosols in closed spaces. Analysis of data related to the spread of SARS-CoV-2 in China seems to indicate the need for close contact between people. Dissemination, in fact, is mainly limited to family members, health workers, and other close contacts [23]. It can also spread when you touch a contaminated surface, known as fomites transmission, and then touch your eyes, nose, or mouth. Although there is a risk that it can be spread through the stool, this risk is believed to be detailed below. The virus is most contagious when people are symptomatic; although spreading may be possible before symptoms appear and for those who never develop symptoms. The European Center for Disease Prevention and Control (ECDC) says that although it is not entirely clear how easily the disease spreads, a person usually infects two or three others [24].

This virus endures for hours or days on exteriors. In particular, it has been discovered that the virus is detectable for one day in cardboard, for a maximum of three days in plastic (polypropylene) and stainless steel and for a maximum of four hours in $99 \%$ copper. This, however, varies based on humidity and temperature. The surfaces can be decontaminated with many solutions (with one minute of exposure to the product obtaining a reduction of 4 or more trunks (99.99\% reduction)), including 78-95\% ethanol (alcohol used in spirits), 70-100\% of 2-propanol (isopropyl alcohol) etc. Soap and detergent are effective even if used correctly; Soapy products break down the fatty protective layer of the virus, deactivate it and release it from the skin and other surfaces [25].

\section{Textile Materials Applied in Preventing the Spread of COVID 19}

There is much equipment those are made up with textile materials and these equipment's are used in the prevention of COVID 19. The descriptions of these materials are given below. Infection prevention and control measures include, but are not limited to hand hygiene, personal protective equipment, and waste management materials. Protective equipment consists of clothing placed to protect healthcare professionals or anyone else from infections [26]. These generally consist of standard precautions: gloves, mask, and dress. For infections transmitted by blood or air, it will include face protection, goggles and a mask, gloves, dress or gown, headgear, rubber boots. Personal protective equipment (PPE) is very essential to prevent coronavirus transmission not only in treatment centers but also in a variety of actions, cleaning, safe handling of waste and burials, and epidemic-related care [27].

\section{Surgical Mask}

Surgical mask is made up of textile materials and abundantly used in giving treatment to the patients infected with COVID 19. Surgical masks are made up with viscose, polyester, polypropylene etc fibers. Surgical masks are mainly in the form of nonwoven but they can also be made up with cotton knitted fabrics [28]. Surgical masks are mandatory in a crowded place where 6 foot of distances is tough to maintain. This will help delay the spread of the virus from people without symptoms or from people who don't know they have contracted with the virus or not. Cloth masks must be worn while physical removal is still practiced. Instructions for creating masks at home are available here. It is essential to reserve N95 surgical masks and respirators for healthcare professionals. Surgical masks should be worn by healthcare professionals during the treatment of COVID-19 patient to spread bacteria from the mouth and nose to droplets and aerosols. To prevent coronavirus, the general public should use cotton masks to reduce the risk of infection [29]. Figure 1 [30] shows the Surgical Mask made up of Textile Materials.

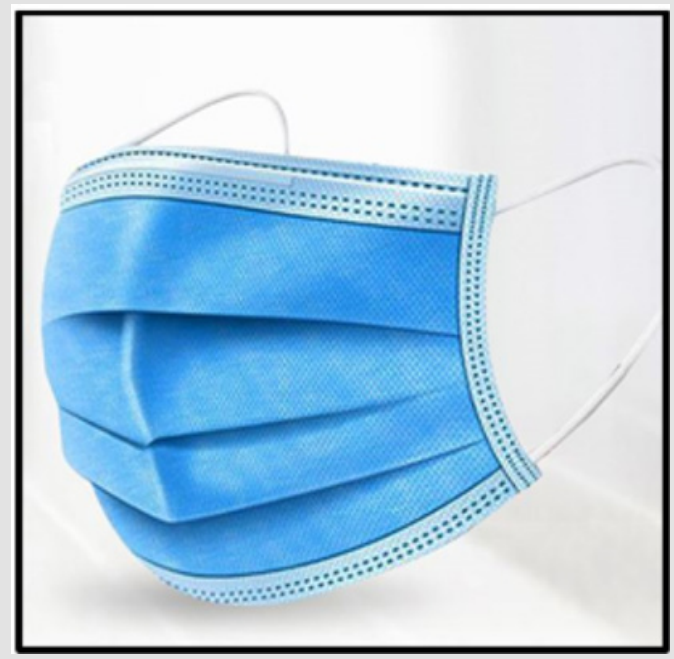

Figure 1: Surgical Mask made up of Textile Materials [30].

\section{Surgical Cap}

Surgical cap is also made up of textile materials and used in giving treatment to the patients infected with COVID 19. Surgical caps are made up with cotton, polyester, polypropylene etc fibers. Surgical caps are also produced with cotton knitted fabrics. The surgical cap that accompanies the surgical gown covers the surgeon's head, and sometimes the hair, the ends. The aim is to prevent contamination of the wound. There are surgical caps to prevent any doctor or nurse from spraying harmful liquids on the scalp and scalp. It also works to prevent hair from affecting the eyesight of doctors. On the other side of the spectrum, hair, or other contaminants such as hair products or dandruff are dangerous for patients [31]. The medical 
caps are made of non-woven viscose and structural type without covering harmful elements during production. Nonwoven fabrics have good air permeability, making medical hats nonwoven and air permeable, sterilized with ethylene oxide. The product is clean and non-toxic, it can effectively prevent cross infections, it is clean, wellcared for, easy to apply and don't worry, it is beautiful and safe to use and it can effectively prevent hair loss. Greater flexibility, faster recovery, longer wear, and apparent dust suppression effects can alleviate buoyancy, debris, microorganisms, etc [32,33]. Figure 2 shows the surgical cap made up of textile materials. Non-woven surgical caps have a normal thickness of $13 \mathrm{~g} / \mathrm{m} 2$ and $50 \mathrm{~g} / \mathrm{m} 2$. Non-woven medical hats have many advantages. For an instance, heavy tensile load, better air penetrability, easily penetrating production, stress-free dispensation, low charge, inexpensive and everyday cost, easy to use, can efficiently restoration hair and stop skating. Non-woven medical parts can consist of a non-woven PP joint section or a non-woven fabric ES, a non-woven fabric, can be used in different sectors. There are several types of content, which can be selected by different users. They may vary according to user preferences, different colors, and types of printing [34].

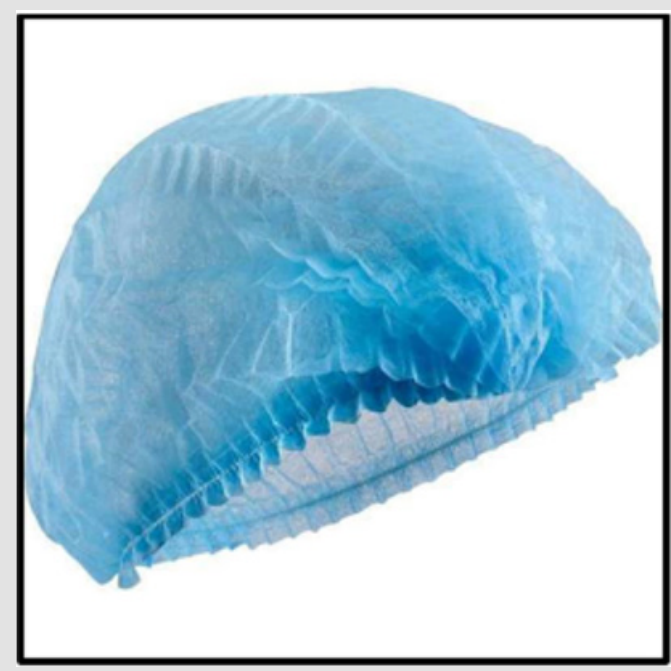

Figure 2: Surgical Cap made up of Textile Material [33].

\section{Surgical Gloves}

Surgical gloves are made up of textile materials and plentifully used to give treatment to the patients infected with COVID 19. Surgical gloves are made up with polyester, polypropylene etc fibers. Surgical gloves are sometimes made up with different blended fibers in composite form. Gloves are must needed product to prevent and treatment to CoVID-19 patient. Medical gloves are made with different polymers, including latex, nitrile rubber, polyvinyl chloride, and neoprene; they are free of dust or powdered with corn starch to lubricate the gloves, making them easier to put on your hands [35]. Corn starch has swapped exasperating tissue powder and lycopodium talc, but corn starch can also stop curative if it infiltrates materials (such as during operation).
Therefore, powder-free gloves are often worn during surgery and other sensitive procedures. Special production processes are used to compensate for the lack of dust. There are two main types of medical gloves: examination and surgery. Medical gloves have new specific sizes with better exactness and compassion and are made to an advanced standard. Examination gloves are available as sterile or non-sterile, while surgical gloves are generally sterile [36].

In addition to medicine, medical gloves are widely used in chemical and biochemical laboratories. Medical gloves offer basic protection against corrosives and surface contaminations like viruses. However, they can be easily penetrated by solvents and various dangerous chemicals. Cotton gloves can be damaged under one-use gloves to decrease the quantity of perspiration formed by exhausting these gloves for an extended time. These gloves can be disinfected and reused. Polyisoprene surgical gloves are made of synthetic polyisoprene which offers properties similar to latex (natural rubber) [37]. Polyisoprene is consisted of a monomer that contains two carbon-carbon double bonds. Similar to most diene polymers, it has a carbon-carbon double bond in its main chain. In fact, polyisoprene has a molecular structure very similar to natural rubber. Polyisoprene is considered a "latex" glove without the harmful proteins present in the latex, which is responsible for latex allergies [38]. Figure 3 [39] shows the surgical gloves made up of textile materials. Like other materials for surgical gloves, polyisoprene surgical gloves are available with an internal polymer lining, facilitating the use of gloves even with wet or dry hands. Of all the materials used for surgical gloves, polyethylene is the most expensive material. However, most manufacturers of surgical gloves offer a selection of polypropylene gloves, as adoption continues to improve due to its late nature. The 3 chief producers of surgical gloves are Molnlycke Health, Ansell Health Care and Cardinal Health care [40].

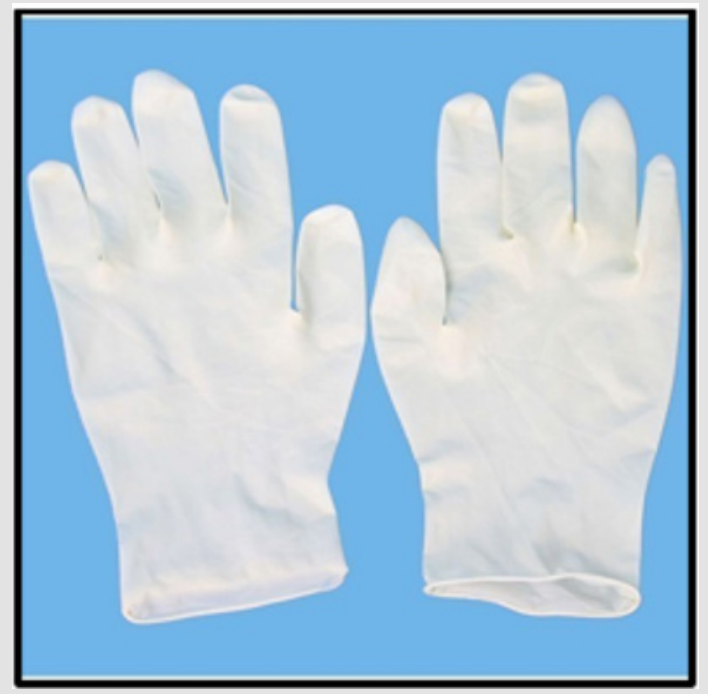

Figure 3: Surgical Gloves made up of Textile Materials [39]. 
The double gloves are put into practice to deplete two layers of medical gloves to defend the risk of contagion from breakage or penetration of gloves by sharp substances during medical actions (used for patients with HIV and hepatitis, surgeons who reduce gloves anti-virus). It would be improved defend patients from contagions conveyed by the physician. A systematic review of the literature indicates that double sliding offers greater protection against the internal puncture of gloves in surgical procedures than using a layer of gloves. But it is unclear whether there is better protection against infections transmitted by surgery [41]. The systematic review further examines whether a surgeon can duplicate the patient's infection. The results of 12 studies with 3,437 participants showed that the double glove reduced the number of perforations in the inner gloves by $71 \%$ compared to a single glove. On average, ten surgeons/nurses involved in 100 operations underwent 172 individual perforations, but only 50 internal gloves would have been perforated with double gloves [42]

\section{Surgical Gown}

Surgical gowns are textile materials those are used to give treatment to the patients infected with COVID 19. It is made up of cotton, polyester, viscose, nylon, polyester or from blended fabrics. Surgical gown is worn to help prevent the user from contaminating vulnerable patients, such as those with weakened immune systems. Clothing is part of an infection control strategy. One-use nonwoven surgical gowns have been approved to stop the issue of polluting elements into the surroundings, which is a probable cause of pollution for the tolerant as like as COVID-19. The surgical sets are poised of non-woven fabrics and polyethylene layers in a weightiness range of 30 to $45 \mathrm{~g} / \mathrm{m} 2$. Cotton, polyester fiber, and polypropylene fiber are used to make the surgical gown, and the fiber structure is nonwoven, woven [43]. Figure 4 shows the surgical gown made up of textile materials.

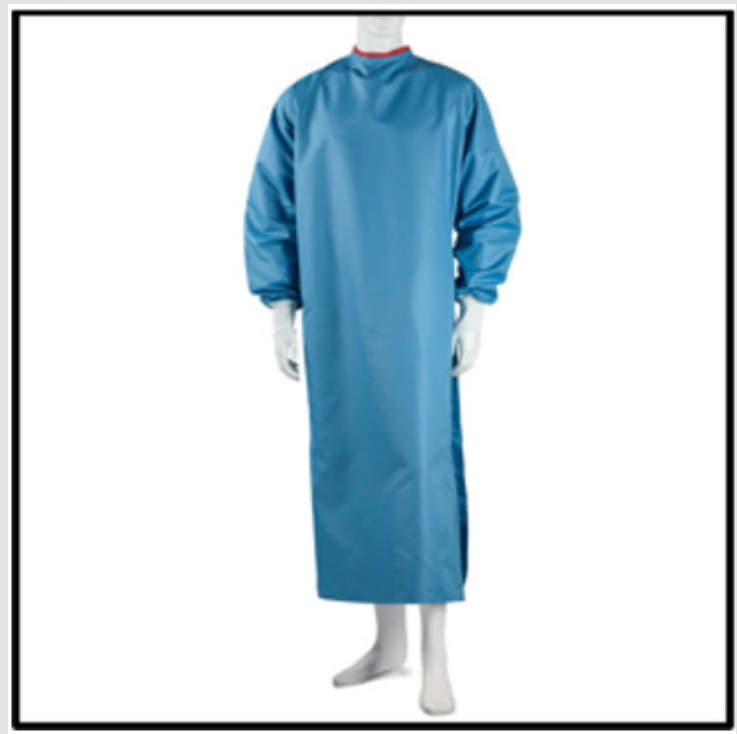

Figure 4: Surgical Gown made up of Textile Materials [44].

\section{Surgical Shoe Cover}

Surgical shoe protectors are made up of textile materials like cotton, polyester, polythene or polypropylene. Surgical shoe covers are very important for several reasons. It may also be made up of heavy-duty nonwoven fabric, which is thicker than normal shoe cover, and may be extremely robust, soft, comfortable and environmentally safe. The operating room must be completely sanitary and sterile. Polythene is a volatile and non-woven material $\mathrm{n}$ means dirt, dust and other particles cannot survive on its surface and since they are non-woven dirt and dust cannot enter the fabric [45]. Medical shoe covers can protect your feet and ankles from stains and unfortunate materials. These covers prevent blood or other liquids from entering your shoes. It helps to keep medical shoes clean and germ-free, providing the key to maintaining specific rooms and environments at the organizational level. It is amazing that such a common product can help a lot of medical personnel, making it really valuable for a low price [46]. Figure 5 shows the surgical shoe cover made up of textile materials. Hospital shoe covers keep the environment clean and germ-free, protect your shoes from scattering and stains, and help prevent accidents. These shoe straps are also affordable and disposable. They have flexible rings around the ankles for strong fit and added protection. For your convenience, most of them are one size fits all, which helps you to provide all the staff efficiently. Most medical shoe covers are nonslip. This means you can walk and walk freely without worrying about slipping onto the hospital floor in a hurry. The steps attached to the medical shoe cover mean additional protection. You can think about doing your job not slipping and getting caught in the middle of an important and complex process [48].

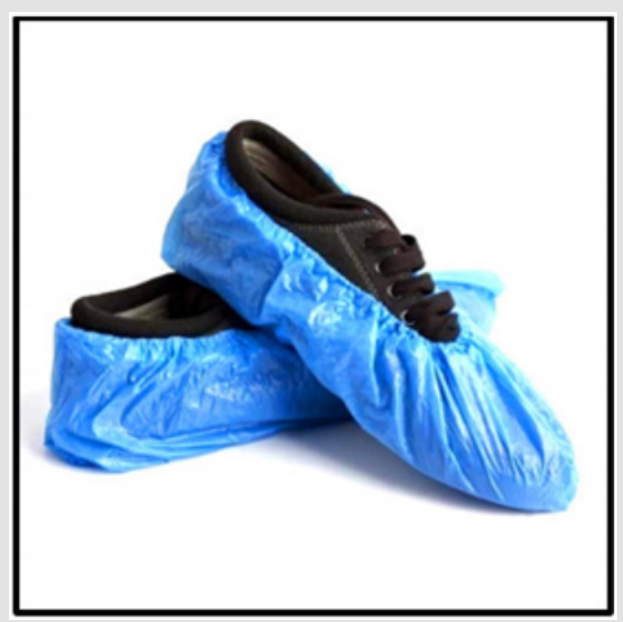

Figure 5: Surgical Shoe Cover made up of Textile Materials [47].

\section{Surgical Sleeve Cover}

Surgical Sleeve Cover is a product that is made up with textile materials, which is used to prevent COVID 19. It can be made up with cotton, polyester, viscose, nylon, polyethylene or 
polypropylene. Even, it can be made up with blending the different types of fibers together. Sometimes it is made up in a nonwoven form. While dealing with the patients of COVID 19, this sleeve cover can give protection to the doctors, nurses and medical assistants. If any germs or liquids come from the COVID 19 infected patients, they cannot enter into the body. Patients bearing dry cough or sneeze cannot do that much harm if it is worn regularly [49]. Figure 6 shows the surgical sleeve cover made up of textile materials.

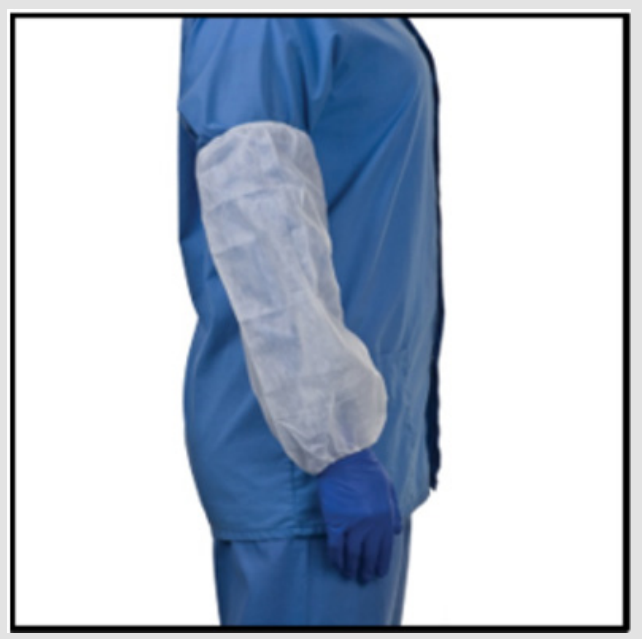

Figure 6: Surgical Sleeve Cover made up of Textile Materials [50].

\section{Disposable Bed Sheet}

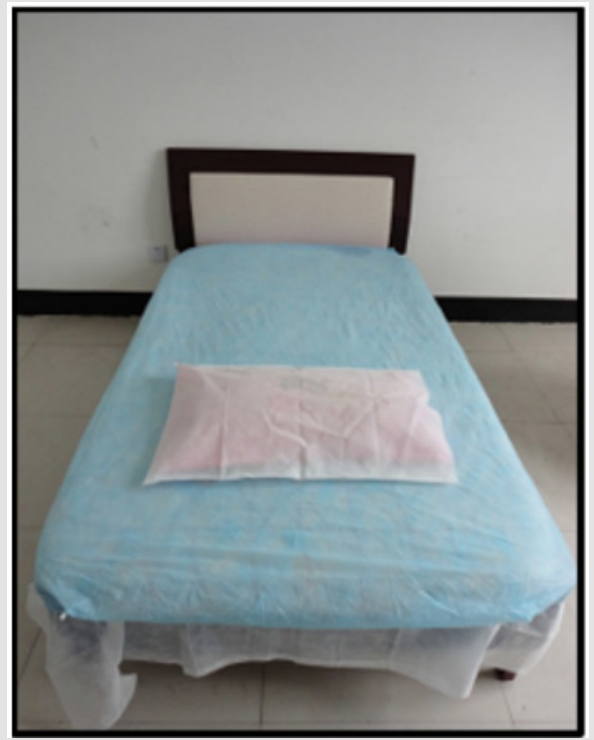

Figure 7: Disposable Bed Sheet made up of Textile Materials [53].

Disposable bed sheets are the products those are made up of textile materials. These sheets are useful while giving treatments to the patients infected with COVID 19. When patients are released from the bed, these sheets may easily be removed from the bed. These sheets are cheap, easily obtainable, biodegradable and easily suit with the patients. It is thick enough to protect the mattress, and saves a lot of effort and time in the morning. However its main advantage is that it is compostable, which means that you do not have to worry about washing it. Removable bed sheets provide a versatile and cost-effective solution while continuing to ensure optimal comfort and hygiene [51]. The production of disposable bed linen depends on the materials used in the factory. However, most manufacturers use soft, woven and organic materials for maximum comfort. Some growers use fiber from the eucalyptus tree. Others use hydrophobic polypropylene, a material that is not only soft and comfortable, but also stain resistant [52]. Figure 7 shows the disposable bed sheet made up of textile materials.

Disposable hospital bed sheets are specifically designed not only to provide comfort but also to help control infection. Its construction also helps reduce the risks of cross contamination coming from washing linen. Most high-quality bed sheets are hypoallergenic, chemical-free such as dyes and bleach, and absolutely soft. Disposable bed sheets have several characteristics like hypoallergenic, eco-friendly, biodegradable, compostable, skin friendly, soft and comfortable, lightweight, stain and pilling resistant etc. They are mainly used in hospitals and other healthcare points. The sheets help in decreasing cross-contamination risks and contagion control [54]. They also defend against spills and stains. This is why they are perfect for medical settings, particularly areas where short stays are must and necessitate repeated bedding changes. In healthcare facilities, the sheets are majorly applied to cover hospital beds, stretchers, surgical beds, and in doctors' rooms. They are basically great for persons with modest or heavy incontinence [55].

\section{Medical Ventilator Bag}

A medical ventilator is a critical piece of medical equipment that literally saves lives every day. The bag of ventilator is a textile material, made up with high-density polyethylene (HDPE) fibers. In case a patient is attacked with COVID-19, ventilators are used for the treatment of patients to facilitate respiration. These machines are used to provide respiratory assistance to patients with difficulties who experience immediate respiratory difficulties on their own [56]. Figure 8 shows the medical ventilator bag made up of textile materials. A medical ventilator increases or replaces the work normally done by the patient's muscles to do the work associated with breathing: inhalation and exhalation of gases to and from the lungs. Medical ventilators are used to help patients in the short term and during recovery from illness or in the long term due to chronic illness. Medical ventilators are available in various types. A simple form is the globe valve mask resuscitator, which is used for short-term respiratory aids by EMT and medical personnel and is manually operated to force air into a patient to sustain life [58]. 


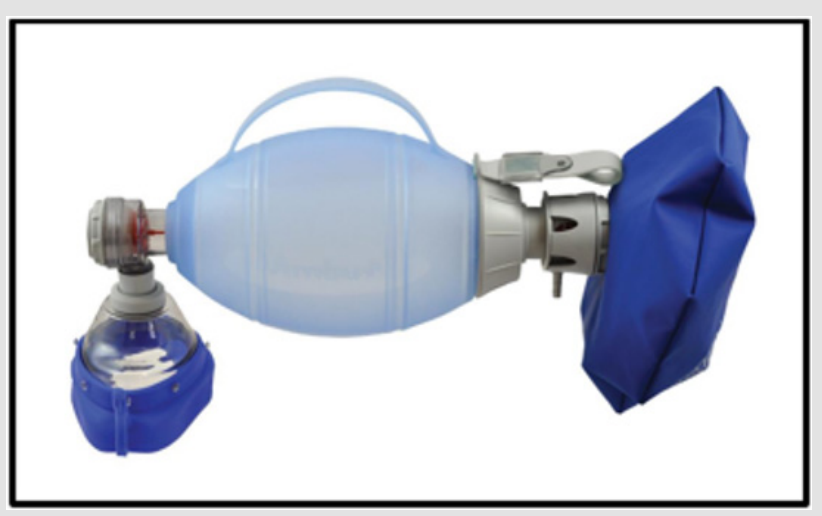

Figure 8: Medical Ventilator Bag made up of Textile Materials [57].

\section{Conclusion}

At last we can say that, the COVID-19 or Coronavirus Pandemic is the global health crisis of our time and the greatest challenge we have faced since World War II. As its arrival in Asia late last year, the virus has extent to all areas excluding Antarctica. The cases increase every day in Africa, America, and Europe. Medical textiles are necessary to fight against this virus all over the world. Textile materials of woven, knit and nonwoven all are important to prepare all the personal protective equipment's (PPE). The world's leading textile manufacturers like China, India, Bangladesh, Vietnam etc are preparing PPE and supplying to the infected countries. Countries fight to slow the spread of the virus by testing and treating patients, tracking contacts, limiting travel, quarantining citizens, and canceling large gatherings like sporting events, concerts, and schools. The pandemic is moving like a wave, a wave that could still crash against those who cannot. But COVID-19 is really further than a health disaster. By focusing on each of the countries it touches, it has the potential to create devastating social, economic, and political crises that will leave deep scars. We are in unknown territory. Many of our communities are now unrecognizable. Dozens of the world's largest cities are deserted because the inhabitants remain inside, by choice, or by order of the government. Around the world, shops, theaters, restaurants, and bars are closing. Every day people lose jobs and incomes, with no way of knowing when normal will return. Small island nations, which rely heavily on tourism, have empty hotels and beaches. We cannot control this situation overnight. We have to take prevention measure before infecting and post treatment measure once we infected. Textile material influences in preparing surgical masks, gowns, gloves etc to protect against this virus. Textile materials or medical textiles have profound impact in the pandemic situation of COVID 19.

\section{References}

1. Parvin F, Islam S, Urmy Z, Ahmed S (2020) The symptoms, contagious process, prevention and post treatment of COVID-19. European Journal of Physiotherapy and Rehabilitation Studies.
2. Parvin F, Islam S, Urmy Z, Ahmed S (2020) A study on the textile materials applied in human medical treatment. European Journal of Physiotherapy and Rehabilitation Studies.

3. Hellewell J, Abbott S, Gimma A, Bosse NI, Jarvis CI, et al. (2020) Feasibility of controlling COVID-19 outbreaks by isolation of cases and contacts. The Lancet Global Health.

4. Baldwin Richard, Eiichi Tomiura (2020) "Thinking ahead about the trade impact of COVID-19." Economics in the Time of COVID-19 59.

5. Lockhart SL, Naidu JJ, Badh CS, Duggan LV (2020) Simulation as a tool for assessing and evolving your current personal protective equipment: lessons learned during the coronavirus disease (COVID-19) pandemic. Canadian Journal of Anesthesia/Journal canadien d'anesthésie pp. 1-2.

6. Bénassy Quéré A, Marimon R, Pisani Ferry J, Reichlin L, Schoenmaker D, et al. (2020) 13 COVID-19: Europe needs a catastrophe relief plan. Mitigating the COVID Economic Crisis: Act Fast and Do Whatever 121.

7. Coyle S, Connolly J, Sabourin M, McNamara E, Curran K, et al. (2017) Textile sensor glove for health monitoring-Application in home assessment of Rheumatoid Arthritis. People.

8. Howard J, Huang A, Li Z, Tufekci Z, Zdimal V, et al. (2020) Face masks against COVID-19: an evidence review.

9. Rodriguez Palacios A, Cominelli F, Basson A, Pizarro T, Ilic S (2020) Textile Masks and Surface Covers-A'Universal Droplet Reduction Model'Against Respiratory Pandemics. medRxiv.

10. Palmieri V, Papi M (2020) Can graphene take part in the fight against COVID-19?. Nano Today p.100883.

11. Bansal CNK, Sharma S, Gautam A. A Study on Impact of COVID-19 a Global Pandemic on Indian Economy: With special Context to Goods and Service Tax.

12. Rothan HA, Byrareddy SN (2020) The epidemiology and pathogenesis of coronavirus disease (COVID-19) outbreak. Journal of autoimmunity p. 102433.

13. Lauer SA, Grantz KH, Bi Q, Jones FK, Zheng Q, et al. (2020) The incubation period of coronavirus disease 2019 (COVID-19) from publicly reported confirmed cases: estimation and application. Ann Intern Med 10: M200504 .

14. Jin X, Lian JS, Hu JH, Gao J, Zheng L, et al. (2020) Epidemiological, clinical and virological characteristics of 74 cases of coronavirus-infected disease 2019 (COVID-19) with gastrointestinal symptoms. Gut 69(6): 1002-1009.

15. Shi H, Han X, Jiang N, Cao Y, Alwalid O, et al. (2020) Radiological findings from 81 patients with COVID-19 pneumonia in Wuhan, China: a descriptive study. The Lancet Infectious Diseases.

16. Gu J, Han B, Wang J (2020) COVID-19: gastrointestinal manifestations and potential fecal-oral transmission. Gastroenterology 158(6): 15181519.

17. Rothan HA, Byrareddy SN (2020) The epidemiology and pathogenesis of coronavirus disease (COVID-19) outbreak. Journal of autoimmunity. p. 102433.

18. Thevarajan I, Nguyen TH, Koutsakos M, Druce J, Caly L, et al. (2020) Breadth of concomitant immune responses prior to patient recovery: a case report of non-severe COVID-19. Nature Medicine 26(4): 453-455.

19. Tindale L, Coombe M, Stockdale JE, Garlock E, Lau WYV, et al. (2020) Transmission interval estimates suggest pre-symptomatic spread of COVID-19. MedRxiv.

20. Zu ZY, Jiang MD, Xu PP, Chen W, Ni QQ, et al. (2020) Coronavirus disease 2019 (COVID-19): a perspective from China. Radiology. p. 200490.

21. Calafiore GC, Novara C, Possieri C (2020) A modified SIR model for the COVID-19 contagion in Italy. arXiv preprint arXiv: 2003.14391. 
22. Maier BF, Brockmann D (2020) Effective containment explains subexponential growth in recent confirmed COVID-19 cases in China. Science.

23. Haushofer J, Metcalf JCE (2020) Combining behavioral economics and infectious disease epidemiology to mitigate the COVID-19 outbreak. Princeton University, March 6.

24. Zeng J, Huang J, Pan L (2020) How to balance acute myocardial infarction and COVID-19: the protocols from Sichuan Provincial People's Hospital. Intensive care medicine 11: 1-3.

25. Agosto A, Giudici P (2020) A Poisson autoregressive model to understand COVID-19 contagion dynamics. Available at SSRN 3551626.

26. Livingston E, Desai A, Berkwits M (2020) Sourcing personal protective equipment during the COVID-19 pandemic. Jama.

27. Abd Elsayed A, Karri J (2020) Utility of substandard face mask options for health care workers during the COVID-19 pandemic. Anesthesia and Analgesia.

28. Givi B, Schiff BA, Chinn SB, Clayburgh D, Iyer NG, et al. (2020) Safety recommendations for evaluation and surgery of the head and neck during the COVID-19 pandemic. JAMA Otolaryngology-Head \& Neck Surgery.

29. Wong J, Goh QY, Tan Z, Lie SA, Tay YC, Ng SY, et al. (2020) Preparing for a COVID-19 pandemic: a review of operating room outbreak response measures in a large tertiary hospital in Singapore. Canadian Journal of Anesthesia/Journal canadien d'anesthésie p.1-14.

30. Medical Disposable 3-ply Anti-virus Masks with melt blown cloth. Anti Dust Breathable Disposable Ear loop Mouth Face Mask. Yuda Medical Equipment Co.

31. Tay JK, Khoo MLC, Loh WS (2020) Surgical considerations for tracheostomy during the COVID-19 pandemic: lessons learned from the severe acute respiratory syndrome outbreak. JAMA OtolaryngologyHead \& Neck Surgery.

32. Kamer E, Çolak T (2020) What to do when a patient infected with COVID-19 needs an operation: a pre-surgery, peri-surgery and postsurgery guide. Turk J Colorectal Dis 30(1): 1-8.

33. Disposable medical cap. India Mart.

34. Fraser JF, Arthur AS, Chen M, Levitt M, Mocco J, et al. (2020) Society of NeuroInterventional Surgery recommendations for the care of emergent neurointerventional patients in the setting of covid-19. Journal of neurointerventional surgery.

35. Repici A, Maselli R, Colombo M, Gabbiadini R, Spadaccini M, et al. (2020) Coronavirus (COVID-19) outbreak: what the department of endoscopy should know. Gastrointestinal endoscopy.

36. Rodrigues Pinto R, Sousa R, Oliveira A (2020) Preparing to perform trauma and orthopaedic surgery on patients with COVID-19. The Journa of Bone and Joint Surgery. American Volume.

37. Ti LK, Ang LS, Foong TW, Ng BSW (2020) What we do when a COVID-19 patient needs an operation: operating room preparation and guidance. Canadian Journal of Anesthesia/Journal canadien d'anesthésie pp.1-3.

38. Szerlip S, Anwaruddin S, Aronow HD, Cohen MG, Daniels MJ, et al. (2020) Considerations for cardiac catheterization laboratory procedures during the COVID-19 pandemic. Cath Cardiovasc Interv.

39. Latex Surgical Gloves Powder Free Non Sterile. Made in China. Source (Hong Kong) Import and Export Co, Limited. Focus Technology Co, Ltd.
40. Lockhart SL, Naidu JJ, Badh CS, Duggan LV (2020) Simulation as a tool for assessing and evolving your current personal protective equipment: lessons learned during the coronavirus disease (COVID-19) pandemic. Canadian Journal of Anesthesia/Journal canadien d'anesthésie p. 1-2.

41. Livingston E, Desai A, Berkwits M (2020) Sourcing personal protective equipment during the COVID-19 pandemic. Jama.

42. Dexter F, Parra MC, Brown JR, Loftus RW (2020) Perioperative COVID-19 defense: an evidence-based approach for optimization of infection control and operating room management. Anesthesia and Analgesia.

43. Wong J, Goh QY, Tan Z, Lie SA, Tay YC, et al. (2020) Preparing for a COVID-19 pandemic: a review of operating room outbreak response measures in a large tertiary hospital in Singapore. Canadian Journal of Anesthesia/Journal canadien d'anesthésie p. 1-14.

44. Surgical gown. Medical Expo.

45. Aminian A, Safari S, Razeghian Jahromi A, Ghorbani M, Delaney CP (2020) COVID-19 outbreak and surgical practice: unexpected fatality in perioperative period. Annals of surgery 272(1): e27-e29.

46. Grasselli G, Pesenti A, Cecconi M (2020) Critical care utilization for the COVID-19 outbreak in Lombardy, Italy: early experience and forecast during an emergency response. Jama.

47. Medsor Impex Disposable Plastic Boot Surgical Shoe Cover. Amazon.in.

48. Adams JG, Walls RM (2020) Supporting the health care workforce during the COVID-19 global epidemic. Jama.

49. Rodrigues Pinto R, Sousa R, Oliveira A (2020) Preparing to perform trauma and orthopaedic surgery on patients with COVID-19. The Journal of Bone and Joint Surgery. American Volume 102(11): 946-950.

50. key Surgical. Protective Sleeves.

51. Wong J, Goh QY, Tan Z, Lie SA, Tay YC, et al. (2020) Preparing for a COVID-19 pandemic: a review of operating room outbreak response measures in a large tertiary hospital in Singapore. Canadian Journal of Anesthesia/Journal canadien d'anesthésie p. 1-14.

52. Chen X, Shang Y, Yao S, Liu R, Liu H (2020) Perioperative care provider's considerations in managing patients with the COVID-19 infections. Transl Perioper Pain Med 7: 216-224

53. Nonwoven disposable bed sheet. Fiber2Fashion.

54. Francom CR, Javia L, Wolter NE, Lee GS, Wine, T, et al. (2020) Pediatric laryngoscopy and bronchoscopy during the COVID-19 pandemic: A four-center collaborative protocol to improve safety with perioperative management strategies and creation of a surgical tent with disposable drapes. International Journal of Pediatric Otorhinolaryngology. p. 110059.

55. Huang Z, Zhao S, Li Z, Chen W, Zhao L, et al. (2020) The battle against coronavirus disease 2019 (COVID-19): emergency management and infection control in a radiology department. Journal of the American College of Radiology 17(6): 710-716.

56. Meng L Qiu H, Wan L, Ai Y, Xue Z, Guo Q et al. (2020) Intubation and Ventilation amid the COVID-19 OutbreakWuhan's Experience. Anesthesiology: The Journal of the American Society of Anesthesiologists.

57. Low cost breathing ventilator. No tech magazine.

58. Brewster DJ, Chrimes NC, Do TB, Fraser K, Groombridge CJ, et al (2020) Consensus statement: Safe Airway Society principles of airway management and tracheal intubation specific to the COVID-19 adult patient group. Med J Aust 16 
ISSN: 2574-1241

DOI: 10.26717/BJSTR.2020.28.004721

Shariful Islam. Biomed J Sci \& Tech Res

(c) (-) This work is licensed under Creative

Submission Link: https://biomedres.us/submit-manuscript.php

$\begin{array}{ll}\text { BIOMEDICAL } & \begin{array}{l}\text { Assets of Publishing with us } \\ \text { RESEARCHES }\end{array} \\ \text { - Global archiving of articles } \\ \text { - Immediate, unrestricted online access } \\ \text { - Rigorous Peer Review Process }\end{array}$

